\title{
Reflexiones sobre la región histórica. Los Altos de Guatemala y Yucatán en la primera mitad del siglo XIX
}

Réflexions sur la région historique. Los Altos de Guatemala et Yucatán dans la première moitié du XIX

siècle

Reflections on the historical region. Los Altos de Guatemala and Yucatan in the first half of the $19^{\text {th }}$ century

\section{Arturo Taracena Arriola}

\section{OpenEdition}

\section{Journals}

Edición electrónica

URL: http://journals.openedition.org/bifea/9298

DOI: $10.4000 /$ bifea.9298

ISSN: 2076-5827

\section{Editor}

Institut Français d'Études Andines

\section{Edición impresa}

Fecha de publicación: 8 abril 2018

Paginación: 41-55

ISSN: 0303-7495

\section{Referencia electrónica}

Arturo Taracena Arriola, «Reflexiones sobre la región histórica. Los Altos de Guatemala y Yucatán en la primera mitad del siglo XIX », Bulletin de l'Institut français d'études andines [En línea], 47 (1) | 2018, Publicado el 08 abril 2018, consultado el 05 noviembre 2020. URL : http://journals.openedition.org/ bifea/9298; DOI : https://doi.org/10.4000/bifea.9298

Les contenus du Bulletin de l'Institut français d'études andines sont mis à disposition selon les termes de la licence Creative Commons Attribution - Pas d'Utilisation Commerciale - Pas de Modification 4.0 International. 


\title{
Reflexiones sobre la región histórica. Los Altos de Guatemala y Yucatán en la primera mitad del siglo XIX
}

\author{
Arturo Taracena Arriola*
}

\begin{abstract}
Resumen
El artículo expone una reflexión teórico-metodológica sobre el concepto de región histórica y, a la vez, es un análisis comparativo sobre dos de ellas: Los Altos de Guatemala y Yucatán en México en la primera mitad del siglo XIX. Para ello, se abordan los siguientes ejes comparativos: su papel en la construcción nacional, su geografía económica, el impacto en estas regiones del régimen de intendencias, el peso de la etnicidad en sus sociedades, el papel de los caudillos y sus alianzas con los sectores subalternos, la construcción ideológica regionalista, la construcción de símbolos identitarios propios, el papel de la Iglesia y el precio territorial pagado luego de su incorporación al estado nacional.
\end{abstract}

Palabras clave: región histórica, regionalismo, territorialización, Hispanoamérica, Los Altos de Guatemala, Yucatán

\section{Réflexions sur la région historique. Los Altos de Guatemala et Yucatán dans la première moitié du XIX ${ }^{\text {ème }}$ siècle}

\section{Résumé}

L'article propose une réflexion théorico-méthodologique sur le concept de région historique et, a la fois, une analyse comparative sur deux d'entre elles : Los Altos de Guatemala et le Yucatan au Mexique pendant la première moitié du XIXème siècle. Dans cette perspective, les axes comparatifs suivants sont abordés : leur rôle dans la construction nationale, leur géographie économique, l'impact dans ces régions du régime d'intendance, le poids de l'ethnicité dans leurs sociétés, le rôle des caudillos et leurs alliances avec les secteurs subalternes, la construction idéologique régionaliste, la construction

* Centro Peninsular en Humanidades y en Ciencias Sociales (CEPHCIS), Universidad Nacional Autónoma de México. E-mail: taracenaarriola@gmail.com 
de symboles identitaires propres, le rôle de l'Église et le prix territorial à payer pour leur incorporation dans l'État national.

Mots clés : région historique, régionalisme, territorialisation, Amérique latine, Los Altos de Guatemala, Yucatán

\title{
Reflections on the historical region. Los Altos de Guatemala and Yucatan in the first half of the $19^{\text {th }}$ century
}

\begin{abstract}
This article presents a theoretical and methodological discussion of the historical region concept as well as a comparative analysis of two historical regions during the first half of the nineteenth century: the highlands of Guatemala and Yucatan in Mexico. The comparative lines that guide this analysis are their role in the national construction, their economic geography, the impact on them by the regime of Intendencias, the ethnicity within their societies, the role played by caudillos and their alliances with subaltern sectors, the ideological construction of regionalism and identity symbols, the role of the Church and the territorial price paid after incorporation into the national state.
\end{abstract}

Keywords: historical region, regionalism, territorialization, Hispanic America, highlands of Guatemala, Yucatan

\section{LAS REGIONES HISTÓRICAS Y SU ESPECIFICIDAD EN HISPANOAMÉRICA}

A mi entender, E. Van Young (1992) ha planteado una propuesta metodológica muy funcional para abordar el tema de la región desde la disciplina histórica al insistir en que hay dos conceptos prioritarios que califican su existencia: la regionalidad y el regionalismo ${ }^{1}$. Al primero lo ha definido como la «cualidad de ser región», es decir, las circunstancias naturales, económicas e históricas que distinguen ese espacio concreto y que pueden ser comparables en calidad de variables con las de otras regiones. ¿Cuáles son esas variables? Rasgos geográficos, patrimonio natural, movimientos migratorios, rutas comerciales, redes comerciales, redes clientelares, redes familiares, procesos de urbanización, fronteras, patrimonio cultural, lengua, etnia. Al segundo lo ha definido como la identificación consciente cultural, sentimental y política que sus habitantes han desarrollado en un largo periodo de tiempo. En otras palabras, es el conjunto de comportamientos culturales y políticos que determinan que los actores regionales luchen por el control del poder

1 Sobre el debate acerca del estudio de las regiones en la perspectiva metodológica de este ensayo, véanse Poche (1985), Miño Grijalva (2002), Melgar (1988), Serrano Álvarez (2001), Martínez Assad (2001), Ibarra (2002) y Malatesta \& Sánchez Mejía (2010). 
interno de la región y frente a los poderes externos que buscan limitarlo. Podría agregar que el regionalismo implica inventar y reinventar la región, apoyándose en fuentes históricas, mitos, leyendas, tradiciones y dimensiones geográficas y, asimismo, dirigir y regenerar a la comunidad regional. Es decir, hacerse de un pasado propio y decidir su estatus frente al poder central. Por tal motivo considero importante estudiar el papel de la ideología como caracterizadora de un grupo o movimiento social determinado (en este caso las élites regionales) y el campo de la cultura (entendido desde su dimensión política) que este produce, el cual tiende a consolidar la memoria territorial de las regiones; en sí mismos, son territorios con una gran interacción de hombres, mercancías, recursos naturales y saberes propios.

En Hispanoamérica, las regiones que hoy estudiamos surgieron durante la Colonia a partir de los polos urbanos que estructuraban el espacio y definían las líneas de fuerza económicas, subrayando que no necesariamente cumplen la misma función ni tienen el mismo rango. Sin embargo, metodológicamente hay que tomar en cuenta fenómenos históricos de origen prehispánico que inciden en la configuración de las mismas, en la medida en que históricamente las territorializaciones 2 en nuestros actuales países se caracterizan por ser un palimpsesto.

Es así que las regiones representan un espacio y un territorio con características propias -integradas a su vez por subregiones-, que al inicio no están necesariamente supeditados a la construcción del Estado nacional, sino que lo anteceden. De ahí que las fronteras de una región no tengan la precisión limítrofe ni respondan necesariamente a sus divisiones administrativas internas. Más bien, son más extensas en la medida en que el Estado nacional tendió, por razones de control administrativo y construcción hegemónica, a desestructurarlas para poder configurar una división administrativa que facilitase la lealtad política y asegurase la soberanía nacional. En síntesis, las regiones son parte del ADN de los Estados nacionales.

En otras palabras, las fronteras de una región se fueron construyendo por la capacidad de territorialización de sus élites y en medio de los pactos y confrontaciones con los grupos subalternos, así como por los efectos surgidos de las migraciones producto de procesos económicos y sociales concretos, sin que por ello dejasen de considerar las especificidades geográficas de su territorio; una geografía que no necesariamente era homogénea, pero que facilitaba la existencia

2 Se entiende por territorialización la acción de un gobierno nacional, regional o local de implantar su hegemonía en un territorio dado de su propio espacio vital —en este caso las regiones históricas - debido, por una parte, a la diferenciación de los asentamientos humanos existentes en él y, por otra parte, a la diversidad geográfica en la que estos están asentados. Es decir, es un acto soberanizador. En ese proceso de apropiación legal y/o ilegal pueden intervenir, además de los hombres, las instituciones, creando así una territorialidad — cualidad que se le otorga a un territorio ya percibido como propio real e imaginariamente-. Para esta definición véanse Métral (1994) y Raffestin (1980). 
de producciones concretas y que marcaba la presencia cultural de grupos étnicos primigenios y migrantes específicos.

La intervención de los centros coloniales motivó a que, a partir de la política descentralizadora borbónica basada en el sistema de intendencias de mediados del siglo XVIII, muchas de estas regiones fuesen potenciadas como entes autónomos, que pasaron a exigir legitimidad, jurisdiccionalidad, institucionalidad y recursos para autoadministrarse; problemática que habría de heredar el sistema republicano ya en plena construcción nacional. Luego de la Independencia, las dinámicas regionales tomaron otros cauces y, por ello, para poder consolidarse, el Estado republicano se inclinó a combatirlas y, como parte de la planificación estatal, buscó rediseñarlas a su antojo. A esto hay que agregar que, bajo la República, surgieron polos urbanos en el siglo XIX e inicios del siglo XX, los que a partir del desarrollo del capitalismo promovieron también el nacimiento de nuevas regiones, las cuales se inscribirían dentro de una articulación más integral.

De hecho, Hispanoamérica no se diferencia de Europa con respecto a estos procesos de surgimiento regional, sino más bien los reproduce en su característica anticentralista y proautonómica. En ese sentido, el modelo en tierras americanas ha sido sobre todo difusionista, aunque es importante subrayar que no se tradujo necesariamente en la reproducción de un comportamiento calcado ni homogéneo, pues se alimentó de la conflictividad que en cada caso produjo la desigualdad entre el centro y las regiones, así como de las propias variables internas. Pero no cabe duda que las regiones permiten la comparación a lo largo del continente y del tiempo. He denominado regiones históricas 3 a la variedad de regiones en las que se da un diálogo propio entre regionalidad y regionalismo en aras de su autonomía frente al Estado central. Estas tienen un origen colonial ligado a la existencia de las provincias y de los corregimientos, pero como entidades territoriales van más allá de estos por efecto de la lógica hegemónica de los mercados y de las producciones agrícolas y extractivas de sus élites, desafiando con ello el orden jurídico territorial republicano.

Quiero añadir una observación metodológica más. El énfasis discursivo en el «aislamiento» como una de las características primordiales de las regiones históricas, en especial en las «periféricas» o marginales, resulta ser algo muy relativo. Primero, porque tal marginalidad tiene una expresión claramente territorial y, segundo, porque —quiérase o no- están vinculadas a otras unidades sociales por razones de fronteras, redes mercantiles y movimientos demográficos. Sin embargo, como

3 En el año 2008 elaboré una propuesta del concepto de región histórica para denominar a aquellas regiones que se construyen marcadas por la disputa política de sus élites con el Estado nacional con miras a potenciar su discurso regionalista, al punto de llegar a equipararlo a un protonacionalismo. Se trata de regiones que manejan una dimensión sociocultural propia, que en el tiempo desemboca en la invención de tradiciones, la creación de símbolos y discursos, las recreaciones historiográficas y la emisión de leyes y decretos de gobierno que favorezcan su particularidad y, sobre todo, su autonomía administrativa con una expectativa puesta en la independencia. Ese proceso político puede ser asumido o relativizado por sus habitantes, y siempre es combatido de forma abierta por el Estado nacional. Para más detalles acerca de este concepto véase Taracena Arriola (2008). 
ideología, el «aislamiento» forma parte del imaginario regional y está relacionado con la crítica que él mismo realiza al comportamiento centralista del poder colonial o republicano y con la necesidad de justificar su autonomía frente a este; un imaginario potenciado por la impronta de la diferencia y el precio que esta paga ante los procesos de homogeneización nacionales.

\section{EL PAPEL CLAVE DE LAS REGIONES HISTÓRICAS EN LA CONSTRUCCIÓN NACIONAL}

Desde la segunda mitad del siglo XVIII (Taracena Arriola, 2008), en Hispanoamérica aparecieron reclamos autonomistas en una serie de provincias, partidos o corregimientos que fueron alentados por la lógica administrativa descentralizadora propuesta por el régimen de Intendencias implantado en 1788. Este buscaba paliar los efectos negativos causados por el abandono o la subordinación en los que muchos de ellos se encontraban, en gran medida, por el papel que desempeñaban en la economía colonial; reclamos de autonomía que vieron una caja de resonancia en el desarrollo de las Cortes de Cádiz entre 1810 y 1820, pero que sobre todo cobraron vida política efectiva en el inicio de la etapa de construcción de los Estados nacionales, a partir de la coyuntura independentista hispanoamericana inaugurada en 1810.

Ello nos lleva a problematizar sobre la conformación de este sentido de pertenencia, esencialmente construido por la élite política y económica de cada una de esas regiones, llegando en algunos casos a manifestar ciertos elementos protonacionalistas 4 por parte de intelectuales, funcionarios, clérigos y caudillos populares opuestos a la centralización del Estado. Un regionalismo que movilizó a las castas y que, en algunos casos como el yucateco, también se propuso hacerlo con los indígenas. Por su parte, para los Estados nacionales decimonónicos, el reto consistió en imponer a las regiones históricas de origen colonial una «comunidad imaginada» global (Anderson, 1993) que reclamase para sí el derecho a definir la identidad, la soberanía política y el control de un territorio nacional; hecho que, en cada una de las ex colonias españolas, se fue decantando por medio de guerras internas y externas, así como por tratados limítrofes con los Estados vecinos.

Precisamente es en esas fronteras de origen colonial donde se encuentran muchas de estas regiones, cuyo regionalismo produjo dinámicas desestabilizadoras del Estado nacional en momentos en los que sus intereses se vieron afectados por él y que, por lo general, se ubican periféricamente con respecto a los intereses centrales. Existen al menos cuatro tipos:

4 El protonacionalismo es entendido a partir de las ideas de Hobsbawm (1992: 55) como la movilización de sentimientos de pertenencia colectiva que ya existen y que pueden funcionar en una escala macropolítica capaz de armonizar con Estados y naciones modernos. 
1. Las que Ilegaron a plantear un separatismo independentista del Estado nacional al cual pertenecían luego de la independencia de España. Ejemplos: Yucatán en México, Los Altos de Guatemala, la Mosquitia en Nicaragua.

2. Las que plantearon la separación de un Estado nacional para integrarse a otro que no era el de origen colonial. Ejemplos: Texas a Estados Unidos, Chiapas a México y Guanacaste-Nicoya a Costa Rica.

3. Las que defendieron un regionalismo con elementos intermedios para la negociación de un autonomía territorial en el seno de sus Estados nacionales de origen. Ejemplos: Sonora y Zacatecas en México y Olancho en Honduras.

4. Las regiones históricas que surgieron a causa de la resistencia al Estado central republicano según dos modalidades. La primera, una región como la regiomontana, cuya capital es Monterrey, en México, surgió a mediados del siglo XIX a la cabeza de un movimiento autonomista fincado en la lucha por el control de las aduanas y de los puestos de frontera localizados en los bajos del Río Bravo a raíz de la emergencia de Texas como región soberana desde 1835. Asimismo, se desarrolló en torno a una economía asentada en la venta de indígenas (bárbaros), el contrabando y el comercio intrarregional (plata, ganado, azúcar, alcoholes), permitiendo el inicio de la industrialización y la consolidación de una fuerza armada propia a partir de 1870. De esa forma, el regionalismo regiomontano se alimentó de movimientos autonomistassecesionistas frente a la debilidad del Estado central mexicano, acosado por la guerra entre federales y centralistas, y la guerra con Estados Unidos. La segunda modalidad se caracteriza por regiones surgidas de la acción bélica de sectores subalternos — como las comunidades indígenas—, que obligaron a algunas regiones históricas como Yucatán y Sonora a aceptar la creación de nuevas territorialidades en su seno (Quintana Roo y Sinaloa, respectivamente) a raíz de las revueltas maya y yaqui (Sauri Riancho, 2016). Son regiones en las que el sentido de pertenencia territorial partió de élites de los sectores subalternos, coincidiendo con una dinámica que F. E. Mallon (2003) ha señalado para la construcción nacional.

\section{LECCIONES EN TORNO A DOS REGIONES HISTÓRICAS: LOS ALTOS DE GUATEMALA Y LA PENÍNSULA DE YUCATÁN}

Estas dos regiones históricas, que he estudiado detenidamente (Taracena Arriola, 1999; 2010; 2013), permiten la comparación no solo por su características internas, sino por su proximidad geográfica y por la coincidencia en el tiempo de sus intentos separatistas durante la década de 1830. Los Altos se separaron de Guatemala en 1838 y fueron reintegrados militarmente en 1841; Yucatán se declaró soberano en 1841 y solo se reintegró a la República mexicana en 1848 sin que se haga jurídicamente efectiva su independencia. Es un período histórico que coincidió también con la separación e independencia de Texas en 1836 y su posterior integración a Estados Unidos en 1845. 
Separatismos motivados en gran medida por la anarquía producida por el enfrentamiento entre centralistas y federalistas, tanto en México como en la República Federal de Centro América, de la cual formaba parte Guatemala. De ahí la importancia del peso de la política en sus procesos internos en la medida en que insidió en su consolidación como regiones históricas y, por lo tanto, en la construcción de su identidad o regionalismo. Los ejes comparativos son:

\section{1. La geografía económica}

Los Altos de Guatemala (fig. 1) y la Península de Yucatán (fig. 2) se encontraban en un área fronteriza entre el virreinato de la Nueva España y el Reino de Guatemala, áreas marginales en el mundo hispánico colonial, en medio de un territorio habitado por los herederos de la civilización maya desde la Península de Yucatán, al norte, hasta la costa guatemalteca del Pacífico. Los Altos de Guatemala se construyeron como región histórica a partir de la hegemonía de la élite de la ciudad de Quetzaltenango y en el caso de Yucatán, de las ciudades de Mérida y Campeche.

En medio de ambas regiones existe una selva, entonces vista como hinterland, que es atravesada por una cuenca fluvial que nace en el altiplano guatemalteco y desemboca en el Golfo de México, con gran cantidad de ríos caudalosos

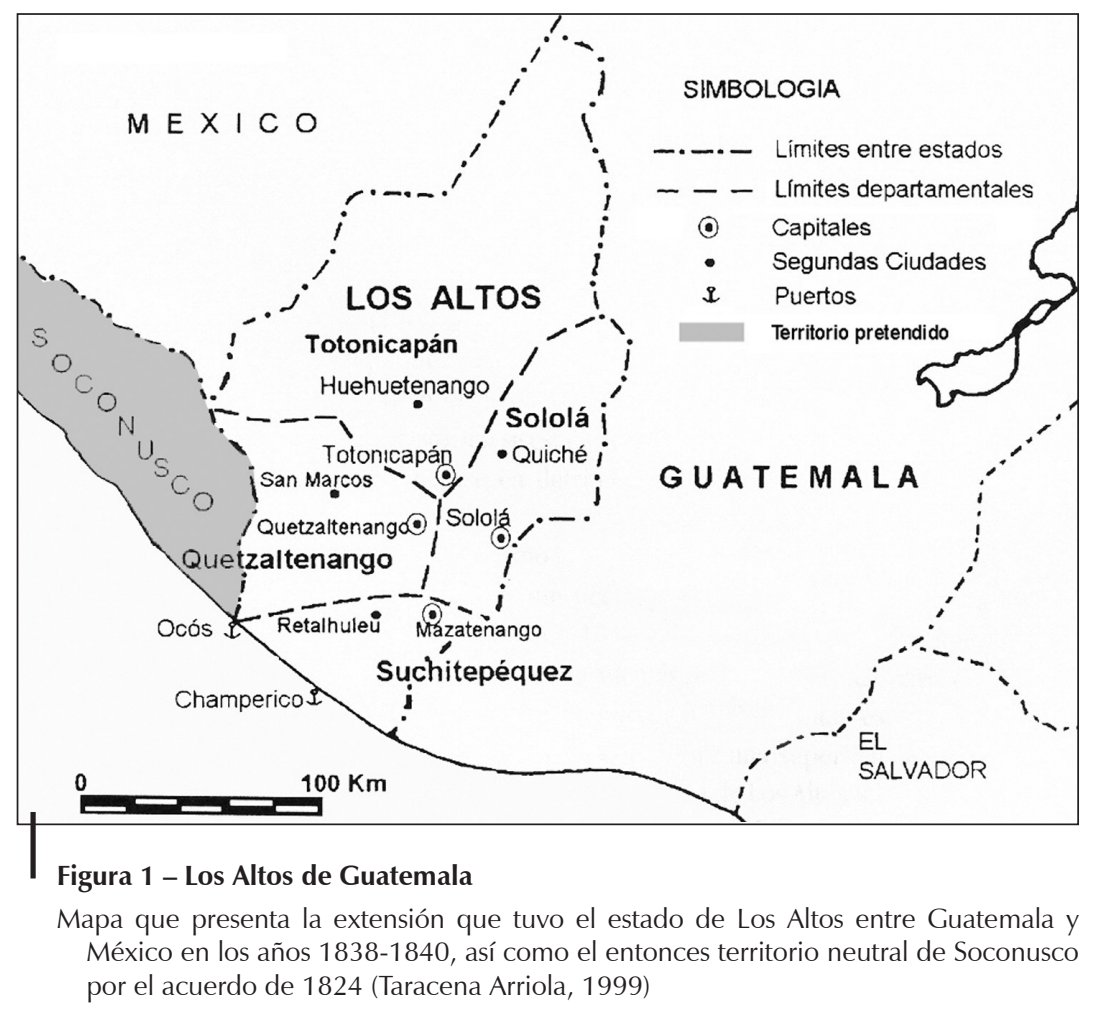




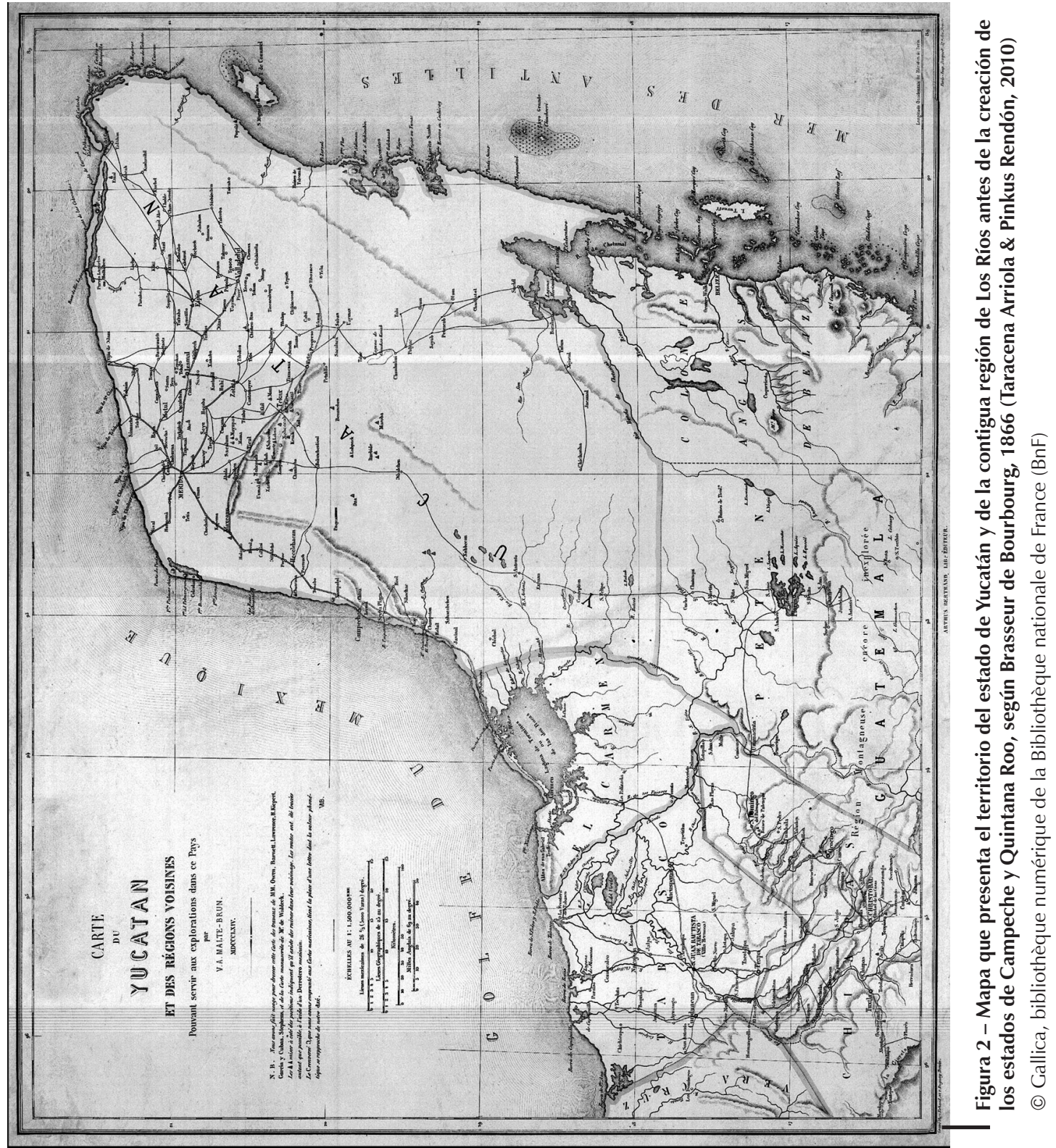


que no solo fertilizaban los bosques, sino que servían de medio de transporte para los hombres, los productos y, sobre todo, el contrabando inglés y español. Esto marcaba la pauta de la territorialización para el caso yucateco a partir de Campeche y Ciudad del Carmen. La selva era considerada como fuente de una riqueza extractiva eterna.

Sin embargo, a nivel de construcción de la riqueza regional, la economía mercantil solar del altiplano altense (lana, granos, utensilios, alimentos, etc.) vio en la Costa Sur (Pacífico) su complemento natural (cacao, sal, pescados y otros productos de la tierra) y, por lo tanto, su espacio a territorializar. Esta es una economía que abastecía al circuito de producción y exportación del añil y la grana que unían Centroamérica con el mercado mundial. Por su parte, la economía extractiva yucateca (palo de tinte y maderas), centrada en la subregión de Los Ríos (PalizadaUsumacinta) y ligada a los mercados de Nueva Orleans, Veracruz, La Habana, Marsella, Burdeos, Bristol y Liverpool, funcionaba sin tener contacto directo con los circuitos de exportación mexicanos en torno a los metales (plata y cobre principalmente).

\section{2. Los beneficios de la implantación del sistema de intendencias}

La implantación del sistema de intendencias en Hispanoamérica a partir de la segunda mitad del siglo XVIII produjo cambios que trajeron beneficios o que generaron descontento a las élites altenses y yucatecas. Por un lado, significó una nueva delimitación jurídico-administrativa en el seno de las colonias y, por otro lado, vino a fortalecer políticamente las exigencias de mayor autonomía por parte de las élites regionales, afianzando su poder. Las propias medidas de mayor control fiscal por parte de la Corona produjeron un fuerte descontento en dichas élites, el cual se convirtió en un discurso abierto en defensa de sus intereses regionales. De ahí que esta realidad permita la comparación analítica de las regiones históricas a lo largo del continente y del tiempo. Este es un ejercicio de comparación necesario para el desarrollo y la salud de las ciencias sociales mexicanas y latinoamericanas en general.

Los Altos de Guatemala pudieron obtener varias oficinas administrativas que conllevaron su ascenso a la calidad de «ciudad». Ello implicó una oficina de alcabalas, otra de correo y una factoría de tabaco, para finalmente lograr la constitución del cabildo de españoles en 1808. De esa forma, su capital, Quetzaltenango, se consolidó no solo administrativamente, sino como centro de intercambios comerciales de todo el occidente de Guatemala. Ello redundaría en el avance de sus hacendados hacia la costa del Pacífico, quienes buscaban beneficiarse del comercio y del contrabando de cabotaje desde Chile hasta California, y favorecer la expansión de la frontera agrícola con productos complementarios a los obtenidos en el altiplano.

Por su parte, para la Capitanía General de Yucatán el sistema implantó más orden administrativo a partir de la creación de las subdelegaciones, las cuales tuvieron 
un mayor control en los partidos en torno a los asuntos de guerra, policía, justicia y hacienda. Sin embargo, los yucatecos no consiguieron abrir el consulado de comercio ni la audiencia que pidieron, causándoles un malestar frente a la Corona. En lo referente a la Real Hacienda, se notó un verdadero cambio al desaparecer las encomiendas y administrarse mejor los fondos de bienes de comunidad, por parte de las autoridades, para hacer frente a la permanente crisis fiscal en razón de las magras entradas por el comercio y de la tributación. Este cambio causó desazón en el seno de los pudientes yucatecos y reforzó su discurso autonomista, sobre todo en el momento de la independencia de 1821.

\section{3. El peso de la etnicidad y, por ende, de las castas frente a los indígenas}

En ambas regiones se contaba con la presencia de una reducida élite criolla que, en la segunda mitad del siglo XVIII, buscó consolidar una alianza con el sector mestizo para poder contrarrestar la impronta de la inmensa mayoría indígena de origen maya; sin embargo, el peso social de los mestizos resultaba ser diverso en Yucatán y en Los Altos de Guatemala. En la primera región, los mestizos (pequeños comerciantes, rancheros, administradores, burócratas de segunda clase, milicianos) estaban en una clara posición subalterna frente a los criollos, mientras que en la segunda, su papel económico y social fue creciendo con el surgimiento de un sector de ellos como hacendados, comerciantes, jefes de milicias y curas. De ahí que en Los Altos de Guatemala se consolidase la identidad «ladina», entendida como la aglutinadora de todos los «no indígenas» (blancos, criollos, mestizos, mulatos e indios aladinados). Ese proceso de bipolaridad étnica en Yucatán solo se consolidó a raíz de la Guerra de Castas de 1847, bajo la denominación «blancos» versus «indios o bárbaros».

\section{4. El papel de los caudillos y su extracción mestiza}

Una característica del sector mestizo fue la producción de caudillos militares ligados a reivindicaciones locales a favor de realidades económicas, sociales locales (comercio de ganado, manejo de contrabando, solución de conflictos, aplicación de justicia) y estatales en contra de la política centralista y a favor del sistema federal — caudillos militares que se evidenciaron en el contexto de las guerras entre centralistas y federalistas-, y que fueron claves en el triunfo de uno u otro bando - triunfo que siempre se dio gracias al apoyo ya sea de la élite o de las poblaciones indígenas-. En Yucatán, a pesar de su victoria militar primero contra los centralistas peninsulares y luego contra las tropas centralistas mexicanas-, los caudillos mestizos (Santiago Imán y los otros caudillos que lo apoyaban) se vieron frenados por el rol que desempeñaban los oficiales de graduación criollos, nativos de las ciudades de Mérida y Campeche, lo que no permitió que su liderazgo alcanzase una dimensión regional total. 
Por su parte, en Los Altos de Guatemala, los caudillos militares mestizos (encabezados por Agustín Guzmán) aglutinaron tanto a la población mestiza como a la población criolla regional. Esta alianza les enajenó el apoyo indígena, el cual fue capitalizado por los caudillos mestizos (Rafael Carrera) de la región oriental del Estado, quienes estuvieron ligados a la élite criolla de la ciudad de Guatemala en defensa del sistema centralista como garante de la unidad territorial del Estado.

\section{5. Los caudillos y sus alianzas con los sectores subalternos (mayas y negros)}

En Yucatán, la alianza de los caudillos mestizos yucatecos (Imán, Gamboa, etc.) con los indígenas mayas se consolidó en la etapa de lucha contra el centralismo (1836-1843), en torno al rechazo por la leva para combatir a los texanos, a favor de la repartición de tierras y de la promesa de abolición de las obvenciones religiosas y, aun, de acceso a la ciudadanía efectiva. Ello llevó a que tal alianza se diese incluso con los huites, habitantes de La Montaña, población nómada y cimarrona que habitaba las zonas oriental y sur de la Península. Sin embargo, a pesar de una aprobación inicial de las autoridades yucatecas en 1843, luego del triunfo militar contra los centralistas, estas abruptamente dieron marcha atrás por considerar necesario cubrir la crisis fiscal producida por la guerra con el trabajo indígena y para evitar que las reformas produjesen en su seno nuevas reivindicaciones.

En Los Altos de Guatemala, con el establecimiento del Estado separatista en 1838, se dio una ruptura con las comunidades indígenas, principalmente las k'ichés, en la medida en que les significó el pago de más impuestos, la instauración de nuevas alcabalas, el trabajo forzado en la construcción y el mejoramiento de carreteras. Ello hizo que estos buscasen la alianza con los centralistas, ya que tradicionalmente el poder central había sido un mediador frente a las disputas entre las comunidades indígenas y los poderes regional y local altenses. Una alianza que, en el caso de Yucatán, el poder central mexicano estaba distante de poder cumplir, sobre todo después de su derrota militar frente a los ejércitos yucatecos en 1843. Por esta razón, cuatro años después se mantendría al margen de la Guerra de Castas que estalló con la sublevación maya de julio de 1847. Sin embargo, vale la pena señalar que, en ambos casos, la intervención militar del centro de poder funcionó como elemento desestabilizador de estas élites regionales; es decir que más allá de la reivindicaciones seculares en contra de la subordinación, los levantamientos indígenas se dieron fundamentalmente por razones objetivas y subjetivas coyunturales.

Finalmente hay que señalar que en Los Altos de Guatemala la forma que adquirió la denominada «Guerra de Castas» fue de corta duración y estuvo caracterizada por la limpieza étnica de ladinos que los indígenas realizaron inmediatamente después de la derrota militar altense a manos del ejército guatemalteco en febrero de 1840. Mientras tanto en Yucatán, el estallido maya de 1847 abrió un conflicto que habría de durar cincuenta años, hasta el triunfo militar del ejército mexicano 
en 1902. ¿Por qué en Guatemala fue de corta duración? Por la intervención del poder central que implementó un nuevo pacto social del Estado con las comunidades indígenas por medio de la reimplantación (modificada) de las Leyes de Indias, que daban autonomía a las comunidades pero las marginaban de la conducción de los asuntos estatales. Por su lado, en Yucatán, el ejército yucateco y sus aliados continuaron combatiendo durante varias décadas sin poder lograr una derrota militar de los mayas insubordinados y sin otorgarles un pacto social que los animase a rendirse. Esto se dio cuando el ejército mexicano, victorioso de la insurrección yaqui en el norte del país, se trasladó para combatir a los mayas insurrectos en 1896, con el objetivo de no permitir más la existencia de territorios autónomos debido a la rebeldía de las poblaciones nativas.

\section{6. La construcción de la ideología regionalista}

A nivel ideológico, a raíz de los «descubrimientos» de los viajeros europeos del siglo XIX (Waldeck, Stephens, Morelet, etc.), la cultura indígena primigenia (civilización maya y maya-k'iché) pasó a ser justificadora de la particularidad regional frente a la construcción nacional desde el Centro, tanto en el regionalismo yucateco como en el altense, hasta ser esgrimida como elemento civilizatorio de valor universal para tener cabida en el concierto de las naciones.

A su vez, tal recuperación permitía la subalternidad de los indígenas contemporáneos, alegando que estos o se habían «degenerado» al punto de haber olvidado los conocimientos de sus ancestros o que ellos eran producto de otras tribus que llegaron al territorio mucho más tarde y ya sin los conocimientos de las civilizaciones ancestrales. Sin embargo, diferían en el hecho de que para los altenses la Conquista no había tenido que ver con tal degeneración, ocurrida al final del posclásico, hacia el año 1200, mientras que para los yucatecos esta se había consumado con el exterminio de la clase dirigente a raíz de la llegada de los españoles a inicios del siglo XVI.

Asimismo, el aislamiento geográfico estaba en el origen del sentimiento de abandono económico y político entre los yucatecos por parte de la Ciudad de México; mientras que en el caso de los quetzaltecos, ese sentimiento partió de la opresión de las casas comerciales capitalinas hacia los empresarios altenses.

\section{7. La prensa y la bandera como constructoras de una pedagogía regionalista}

En ambos casos, la prensa regional desempeñó el papel de elemento ideologizador y de mecanismo pedagógico en todos los sectores, tanto alfabetizados como no alfabetizados, en la medida en que la lectura colectiva era algo común en los círculos familiares y sociales. Se trataba de un esfuerzo que permitiese la transmisión de valores regionales con el fin de crear una identidad propia en el presente que se vivía. Así, en Yucatán, además de la prensa oficial, apareció la prensa literaria 
(Museo Yucateco, Registro Yucateco), encargada de la reproducción de textos históricos, leyendas, poemas, descubrimientos arqueológicos, ensayos sobre toponimia, es decir, de crear una memoria en papel. Su éxito estuvo centrado en la implicación de los miembros de la intelectualidad yucateca en tal esfuerzo aun en el orden económico.

En Los Altos de Guatemala la existencia de un reducido número de intelectuales hizo que el periódico alternativo, El Quetzal, fuese más modesto en la difusión de un discurso identitario, aunque no dejó de abordar temas similares a los de la prensa yucateca. A la par, en ambas regiones, el gobierno se dio a la tarea de procurarse sendas banderas que distinguiesen simbólicamente a su territorio del de las repúblicas mexicana y centroamericana.

\section{8. El papel de la Iglesia en la construcción regionalista}

En Los Altos de Guatemala, el encargado del curato, Fernando Antonio Dávila, forzó la creación de una Vicaría para la región desde la que se defendió la independencia altense, apoyándose en el hecho de que un prominente sacerdote (José Matías Quiñónez Manzanares) era el presidente del Congreso soberanista. Al no haber obispado, la territorialidad religiosa estaba definida por los curatos, que en general coincidían con el área de las alcaldías mayores y menores.

En Yucatán, la diócesis que existía desde el siglo XVI se mantuvo al margen de las proclamas separatistas, dejando que estas estuviesen en manos de sacerdotes con cargo de diputados (Domingo Faxardo y José Manuel Berzunza); sacerdotes que desde la década de 1820 planteaban las reivindicaciones territoriales yucatecas sobre Petén y Belice. La razón era el traslape territorial entre la audiencia y el obispado de Yucatán, siendo más extenso el territorio de este último, pues cubría tierras peteneras y beliceñas.

\section{9. La imposición del fraccionamiento territorial interno a raíz de la reintegración}

Dicho fraccionamiento territorial se constata en que habiendo sido Yucatán un solo estado de la República mexicana hasta 1862, vio luego la creación no deseada en su territorio de dos nuevos estados (Campeche y Quintana Roo) por orden del gobierno federal. Asimismo, Los Altos de Guatemala, conformado originalmente por tres departamentos (Quetzaltenango, Totonicapán y Sololá), luego de su independencia negoció la creación de un cuarto departamento (Suchitepéquez). No obstante, a raíz de que en 1840 estos departamentos altenses fueron reintegrados a Guatemala, el gobierno central parceló su territorio en cuatro departamentos más (San Marcos, Huehuetenango, Retalhuleu y Quiché) durante la segunda mitad del siglo XIX. 


\section{CONCLUSIONES}

La creación de una región en Hispanoamérica normalmente suele anteceder al del Estado nacional, de ahí que sus características primigenias no estén necesariamente supeditas al comportamiento de este último. Así, durante los procesos de independencia, el Estado colonial se mostró como un conglomerado de regiones, cada una de ellas con problemáticas, intereses, fronteras y culturas particulares. Por tal razón, las regiones van a incidir directamente en la construcción del Estado nacional y, a la vez, este tenderá a desestructurarlas o reestructurarlas conforme va consolidando su propio proceso institucional, casi siempre con una fuerte lógica centralista. En ese enfrentamiento, aquellas regiones que por sus cualidades socioeconómicas (regionalidad), así como por la identificación consciente en el tiempo de su élite y de buena parte de sus pobladores (regionalismo), se enfrentaron política, económica y culturalmente al poder del Centro y al de sus agentes, tienen el carácter de regiones históricas. Por ello, estas buscaron afianzar su autonomía y, por qué no, convertirse a la vez en un nuevo Estado nacional. Yucatán en México y Los Altos de Guatemala fueron un ejemplo de ello.

\section{Referencias citadas}

ANDERSON, B., 1993 - Comunidades imaginadas. Reflexiones sobre el origen y difusión del nacionalismo, 320 pp.; México, D. F.: Fondo de Cultura Económica.

BRASSEUR DE BOURBOURG, E.-C., 1866 - Monuments anciens du Mexique. Palenqué et autres ruines de l'ancienne civilisation du Mexique. Collection de Vues, Bas-Reliefs, Morceaux d'Architecture, Coupes, Vases, Terres cuites, Cartes et Plans; París: Arthus Bertrand.

HOBSBAWM, E. J., 1992 - Naciones y nacionalismo desde 1780, 212 pp.; Barcelona: Crítica.

IBARRA, A., 2002 - Un debate suspendido: la historia regional como historia finita (comentarios a una crítica fundada). Historia Mexicana, LII (1): 241-259.

MALATESTA, J. \& SÁNCHEZ MEJÍA, H. R., 2010 - Construir la nación, buscar la región: Paisaje, relaciones sociales e historia en la literatura del Valle del Cauca, 1880-1940, 125 рр.; Cali: Programa Editorial de la Universidad del Valle.

MALLON, F. E., 2003 - Campesino y nación. La construcción de México y Perú poscoloniales, 583 рр.; México, D. F.: Centro de Investigaciones y Estudios Superiores en Antropología Social (Ciesas), El Colegio de San Luis, El Colegio de Michoacán.

MARTíNEZ ASSAD, C., 2001 - Los sentimientos de la región: del viejo centralismo a la nueva pluralidad, 439 pp.; México, D. F.: Editorial Océano.

MELGAR, R. M., 1988 - La región etnocultural (una categoría analítica-problemática). Anthropos, 2-3: 3-14. 
Reflexiones sobre la región histórica. Los Altos de Guatemala y Yucatán en la primera mitad del siglo XIX

MÉTRAL, G., 1994 - Réflexions sur les territorialités collectives dans un espace transfrontalier. Le Globe. Revue genevoise de géographie, 134: 27-30.

MIÑO GRIJALVA, M., 2002 - ¿Existe la historia regional? Historia mexicana, LI (4): 867897.

POCHE, B., 1985 - Une définition sociologique de la région? Cahiers Internationaux de Sociologie, LXXIX: 225-238.

SAURI RIANCHO, D. M., 2016 - Élites y desigualdad regional. Los casos de Yucatán y Nuevo León; Mérida, Yucatán: Centro de Investigaciones y Estudios Superiores en Antropología Social (CIESAS Peninsular). Tesis doctoral.

RAFFESTIN, C., 1980 - Pour une géographie du pouvoir, 249 pp.; París: Librairies Techniques (Litec).

SERRANO ÁLVAREZ, P., 2001 - Interpretaciones de la historiografía regional y local mexicana, 1968-1999. Los retos teóricos, metodológicos y líneas de investigación. Revista de História Regional, 6 (2): 113-125.

TARACENA ARRIOLA, A., 1999 - Invención criolla, sueño ladino, pesadilla indígena: Los Altos de Guatemala, de región a Estado (1740-1871), 402 pp.; Antigua Guatemala: Centro de Investigaciones Regionales de Mesoamérica (CIRMA).

TARACENA ARRIOLA, A., 2008 - Propuesta de definición histórica para región. Estudios de Historia Moderna y Contemporánea de México, 35: 181-204.

TARACENA ARRIOLA, A., 2010 - De la nostalgia por la memoria a la memoria nostálgica. La prensa literaria en la construcción del regionalismo yucateco en el siglo XIX, 428 pp.; Mérida: Universidad Nacional Autónoma de México, Centro Peninsular en Humanidades y Ciencias Sociales.

TARACENA ARRIOLA, A., 2013 - De héroes olvidados: Santiago Imán, los huites y los antecedentes bélicos de la Guerra de Castas, 223 pp.; Mérida: Universidad Nacional Autónoma de México, Centro Peninsular en Humanidades y Ciencias Sociales (CEPHCIS).

TARACENA ARRIOLA, A. \& PINKUS RENDÓN, M., 2010 - Cartografía histórica de la Península de Yucatán, 1821-1970, CD; Mérida: Universidad Nacional Autónoma de México, Dirección General de Asuntos del Personal Académico, Centro Peninsular en Humanidades y Ciencias Sociales (CEPHCIS).

VAN YOUNG, E., 1992 - La crisis del orden colonial. Estructura agraria y rebeliones populares en Nueva España, 1750-1821, 515 pp.; México, D. F.: Alianza Editorial. 